\title{
O olhar do Professor sobre a Inclusão na Educação Infantil da Rede Pública do Rio de Janeiro
}

Débora Videira Gonçalves (Departamento de Educação Inclusiva e Continuada - Faculdade de Educação - Universidade do Estado do Rio de Janeiro - Graduação; Professora da Educação Infantil da Prefeitura do Rio de Janeiro)

https://orcid.org/0000-0002-8981-8137

Flavia Barbosa da Silva Dutra - Departamento de Educação Inclusiva e Continuada - Faculdade de Educação - Universidade do Estado do Rio de Janeiro - Professora Doutora UERJ)

https://orcid.org/0000-0002-0812-6092

\section{Resumo}

O objetivo deste artigo é trazer a percepção de um grupo de professores sobre a inclusão de crianças com deficiência na educação infantil da rede pública, tendo em vista todos os problemas e dificuldades enfrentados pela inclusão, realizando uma breve abordagem histórica com base nas leis sobre a inclusão, relacionando inclusão e infância, identificando a formação necessária para professores e apontando a atual situação das escolas do Rio. Através de uma pesquisa preliminar de dados, aplicada a professores da prefeitura do Rio foram obtidos diferentes olhares do professor sobre a inclusão, permitindo concluir que prevalece o olhar positivo sobre a inclusão, porém com muitos desafios e obstáculos que podem ser superados a partir de políticas pública de inclusão.

Palavras-chave: Inclusão. Escola pública. Pesquisa preliminar de dados. Educação infantil.

Data de submissão: 01/09/2018

Data de aprovação: 02/10/2018

\section{Abstract}

The aim of this article is to bring the perception of a group of teachers about the inclusion of children with disabilities in the public education of children, in view of all the problems and difficulties faced by inclusion, by carrying out a brief historical approach based on the laws on inclusion, relating inclusion and childhood, identifying the necessary training for teachers and pointing out the current situation of schools in Rio. Through a preliminary data survey, applied to teachers of the city of Rio, different views of the teacher about inclusion were obtained, allowing to conclude that the positive view on inclusion prevails, but with many challenges and obstacles that can be overcome through public inclusion policies.

Keywords: Inclusion, Public school. Preliminary data search. Early childhood education.

\section{Introdução}

O objetivo deste artigo é trazer a percepção de um grupo de professores sobre a inclusão de crianças com deficiência na educação infantil da rede pública, tendo em vista todos os problemas e dificuldades 
enfrentados pela inclusão. O problema que se quer investigar é: Qual a percepção do professor sobre a inclusão de alunos com deficiência em sala de aula?

A inclusão começa a partir de crenças de que a educação é um direito humano básico e o fundamento para uma sociedade mais justa (AINSCOW, 2009).

A principal relevância deste estudo é a reflexão sobre a visão do professor em relação ao seu trabalho que faz a diferença. A partir das perspectivas que o professor tem com relação ao seu aluno, ele pode desenvolver trabalhos de diferentes maneiras. Desta maneira, será apresentada uma breve abordagem histórica com base nas leis sobre a inclusão, relacionando inclusão e infância, identificando a formação necessária para professores e apontando a atual situação das escolas do Rio.

Olhar é um instrumento que serve para refutar as diferenças e lutar contra as resistências. Pior que o olhar da discriminação é aquele que oculta a realidade, o olhar da indiferença em relação ao outro. O mesmo toca de forma silenciosa e fere o outro (BARROS, 2003).

Educação inclusiva e a educação infantil vivem em processo contínuo de reconhecimento da criança como ser social que produz conhecimento e cultura que nela é produzida e reproduzida.

A inclusão da creche nas LDB de 1996, como a primeira etapa da Educação Básica juntamente com a Pré-Escola, trouxe um novo significado a essa instituição, que deixou de ser vista como uma segunda casa, aspecto assistencialista, para ocupar um espaço dentro da educação e cuidado com as crianças. No entanto, o acesso a essas vagas ainda é difícil.

A educação infantil por si só, já carrega um caráter superficial e sem importância a partir da não necessidade de frequentá-la até os 3 anos, deixando de lado a importância dessa primeira etapa da educação básica na vida do ser humano.

É importante que a inclusão no sistema educacional se inicie na Educação Infantil.

A família da criança com deficiência precisa não apenas acreditar nos benefícios da inclusão como também reconhecer que seus filhos têm direito a ela. Segundo Biaggio (2007), a legislação penal no art. $8^{\circ}$, da Lei $n^{\circ} 7.853 / 89$ diz ser crime de conduta frustrar, sem justa causa, a matrícula de um aluno com deficiência, a exclusão é crime.

O contato das crianças entre si reforça atitudes positivas, ajudando-as a aprender a ser sensíveis, a compreender, a respeitar e a crescer, convivendo com as diferenças e as semelhanças individuais entre seus pares. TODAS as crianças, sem distinção, podem beneficiar-se das experiências obtidas no ambiente educacional. Os alunos com deficiência, em especial, quando em ambientes inclusivos, podem apresentar melhor desempenho no âmbito educacional, social e ocupacional. Eles aprendem como atuar e interagir com seus pares no mundo "real" (FERREIRA; GUIMARÃES, 2003, p. 177).

As relações entre seus pares possibilitam a troca que potencializa o desenvolvimento a partir das experiências. As relações interativas entre crianças com deficiência ou não, refletem aquilo que vivem, palavras e atos em seus cotidianos.

Nesse sentido, entendemos que tanto o bebê sem deficiência quanto aquele que tem alguma deficiência, transtorno global do desenvolvimento ou altas habilidades/super- 
dotação, ao estar em contato com outras crianças e adultos em um processo inclusivo, podem, desde a mais tenra idade, se apropriar das características tipicamente humanas e superar estágios de desenvolvimento (DRAGO, 2014, p.70).

Nos primórdios da humanidade, as pessoas com deficiência eram segregadas e excluídas do meio social. Atualmente houve um avanço, porém a inclusão não ocorre de maneira efetiva, pois grande parte da sociedade marginaliza as pessoas com deficiência.

Através de lutas contra a marginalização das pessoas com deficiência, consolidou-se no Brasil, a filosofia da Normalização. Este conceito de Educação Especial defende que todas as pessoas com deficiência tenham direito de viver na sociedade como as pessoas ditas normais. Após essa filosofia, criou-se o paradigma educacional chamado Integração, que oferecia aos alunos com deficiência um ambiente escolar menos excludente. Geralmente eles frequentavam as classes especiais e, somente se apresentassem condições para acompanhar a turma, iriam para as classes regulares, tendo eles que se adaptarem ao ambiente, independentemente de suas necessidades físicas ou intelectuais.

A busca por alternativas menos segregativas vem se intensificando a partir dos anos 90; a política de educação inclusiva é de responsabilidade dos governos e do sistema escolar.

\section{Metodologia}

A metodologia utilizada pressupôs pesquisa qualitativa e pesquisa bibliográfica, na busca de conceitos que pudessem validar a inclusão em sala de aula da pessoa com deficiência. Foi realizada também uma pesquisa preliminar de dados para consolidar o problema aqui enunciado, sobre a percepção do professor sobre este tema.

\section{Uma breve abordagem histórica com base nas leis sobre a inclusão}

Ao longo dos anos, a visão sobre a pessoa com deficiência foi se modificando, como se observa, a seguir, em algumas datas históricas selecionadas. Segundo Jannuzzi (2004), no Brasil-Colônia do século XVI, as pessoas com deficiência passavam despercebidas, devido à sociedade desempenhar atividades pouco complexas.

De acordo com Carmo (1991), no Brasil durante o período colonial e imperial, raramente se encontravam pessoas com deficiência, apenas quando se acidentavam na guerra ou na selva. Nessa época, as deficiências não eram notadas, pois ao nascer eram sacrificadas pelos próprios pais. No que concerne à educação escolar:

A educação escolar não era considerada como necessária, ou mesmo possível, principalmente para aqueles com deficiências cognitivas e /ou sensoriais severas. $O$ trabaIho educacional era relegado a um interminável processo de "prontidão para a alfabetização", sem maiores perspectivas já que não havia expectativas quanto à capacidade desses indivíduos desenvolverem-se academicamente e ingressarem na cultura formal (GLAT; FERNANDES, 2005, p. 36-37).

No fim do Império, foi disseminado pelo país o atendimento médico-pedagógico. Colocamos aqui 
uma cartografia do tempo sobre o assunto.

Em 1930 - Helena Antipoff vem ao Brasil preocupando-se com as pessoas com deficiência intelectual.

Em 1961 - Cria-se a lei da LDB n4024/61, para alunos com deficiência, dizendo que eles deveriam se enquadrar no sistema geral de educação. Ou seja, aqui é o aluno que tem que se adequar ao sistema/ escola, senão está fora.

Em 1988 - A Constituição Federal garante que a educação para pessoas com deficiência deve ocorrer preferencialmente na rede regular de ensino, com o direito ao atendimento especializado.

Eis alguns documentos legais acerca do direito da educação para todos:

Em 1990 - Declaração de Jomtien, que visa estabelecer compromissos mundiais para garantir a todas as pessoas os conhecimentos básicos necessários a uma vida digna, visando a uma sociedade mais humana e mais justa.

Em 1994 - Declaração de Salamanca: é um dos principais documentos. Seu objetivo é fornecer diretrizes básicas para a formulação e reforma de políticas e sistemas educacionais de acordo com o movimento de inclusão social.

Em 1996 - Lei de Diretrizes e Bases no 9394: estabelece que o atendimento às pessoas com necessidades educacionais deve ocorrer preferencialmente na rede regular de ensino, permitindo a existência de classes e escolas especiais quando não for possível a adequação desses alunos nas classes comuns do ensino regular.

Em 2001 - Lei 10.172: aprova o PNE, estabelecendo 28 objetivos e metas para educação das pessoas com Necessidades Especiais.

Em 2009 - Resolução No 04 CNE/CEB: as Diretrizes Operacionais para o Atendimento Educacional Especializado na Educação Básica - Modalidade Educação Especial, especifica que os alunos com deficiência, transtornos globais do desenvolvimento e altas habilidades/superdotação precisam ser matriculados nas classes comuns e também no Atendimento Educacional Especializado (AEE).

Em 2011 - Decreto n 7.612: institui o Plano Nacional dos Direitos da Pessoa com Deficiência-Plano Viver sem Limite.

Esses e outros documentos afirmam a obrigatoriedade na rede regular de ensino para todos, e à escola compete a organização para o atendimento das crianças com uma educação de qualidade.

\section{Inclusão e Infância}

O princípio básico da inclusão é que todos os estudantes independentemente das condições socioeconômicas, raciais, culturais ou de desenvolvimento, sejam recebidos e acolhidos na escola regular. E essa escola deve se adaptar para receber esses estudantes, pois ela é um meio capaz de diminuir o preconceito e as atitudes discriminatórias promovendo uma sociedade mais inclusiva.

Um dos aspectos a se considerar dentro da proposta da Educação Inclusiva na Educação Infantil é a diminuição do número de alunos por sala, de maneira a facilitar a interação dos seus membros e o atendimento as especialidades de cada um. Hoje, na Prefeitura do Rio de Janeiro, na educação infan- 
til, há, no máximo, 25 alunos por turma; se existir na sala um aluno especial, haverá a redução de 2 alunos.

Entretanto, não basta apenas o acesso à matrícula e sim a garantia da permanência desses estudantes na escola.

É importante enfatizar também que a Educação Inclusiva não se resume à matrícula do aluno com deficiência na turma comum ou à sua presença na escola. Uma escola ou turma considerada inclusiva precisa ser, mais do que um espaço para a convivência, um ambiente onde ele aprenda conteúdos socialmente valorizados pela todos os alunos da mesma faixa etária. O objetivo desta proposta é a possibilidade de ingresso e permanência do aluno na escola com sucesso acadêmico, e isso só poderá se dar a partir da atenção às suas peculiaridades de aprendizagem e desenvolvimento (GLAT, 2007, p.20).

Porém, há de se levar em consideração que é necessário observar o melhor para o educando, avaliando e identificando as necessidades de aprendizagem específicas que o aluno apresenta em sua interação com o contexto educacional.

O que tem acontecido atualmente é que, tanto no ensino especial quanto no ensino regular, o fracasso escolar tem sido presente, e isso ocorre por uma série de fatores: professores despreparados, falta de acessibilidade, falta de material adaptado. E, especificamente na educação infantil, nem sempre há um mediador para cada aluno da escola; se a criança não está mais na idade de creche, utiliza fraldas ou não se alimenta de maneira "normal", ela não pode ficar na sozinha. Nesse caso, um responsável tem que ficar todo o tempo em que a criança permanece na escola, o que dificulta ainda mais a permanência dessas crianças na educação infantil.

Para que essas crianças obtenham sucesso escolar é preciso que haja uma crescente mudança no processo pedagógico implicando ações políticas, financiamento, organização técnica dos sistemas de ensino, melhoria das condições de trabalho docente e formação docente.

Nessa perspectiva, o Atendimento Educacional Especializado (AEE), é utilizado para suprir as demandas dos alunos com necessidades educacionais especiais, através de um profissional especializado, promovendo a aprendizagem. É uma espécie de complementação do ensino regular para eliminar algumas barreiras. Na Constituição Federal 1988, Art. 208, inciso III, diz que o AEE deve ser feito preferencialmente na rede regular de ensino. Infelizmente a expressão "preferencialmente" deixa margem para questionamentos, induz a diversas interpretações.

Segundo a Resolução n.4/2009, o Art. 5 aponta que o AEE é realizado, prioritariamente, na sala de recursos multifuncionais da própria escola ou em outra escola de ensino regular, no turno inverso da escolarização, não sendo substitutivo às classes comuns.

Segundo Braun e Vianna (2011), os professores de várias redes de ensino do Rio de Janeiro percebem algumas dificuldades quanto ao atendimento realizado nas salas de recursos: dificuldades de garantir a presença no contraturno, quando os horários são muitos distantes um do outro; a alimentação, que nem sempre é garantida; baixa oferta. Há professores e até escolas que interpretam que a turma regular é só para o aluno "socializar", e a sala de recursos é o lugar onde ele vai aprender de fato; há também escolas que optam por utilizar o mesmo turno e não o turno oposto, para evitar evasão e apoiar os professores das classes regulares. Outro problema: nem sempre os materiais que chegam são adequados, ou o professor não sabe utilizar, ou a escola não tem um espaço adequado para ser a sala de recursos.

Uma mudança de olhar é decisiva, pois ao considerar que as necessidades educacionais especiais se 
encontram na relação entre o processo de aprendizagem do aluno e a proposta curricular desviamos o foco de atenção, anteriormente centrado nas dificuldades do aluno, direcionando-o para as respostas educacionais que a escola precisa lhe proporcionar.

\section{Formação de professores}

A qualidade da formação docente tem um papel importantíssimo para sucesso dos educandos, porém não é a única variável que interfere no sucesso da aprendizagem dos educandos.

Visando o grau de escolaridade dos professores, o artigo 62 da LDB diz que a formação dos professores necessária para atuarem na educação básica é a licenciatura plena de graduação, mas permite que, na Educação Infantil e no Ensino Fundamental I, o professor tenha apenas o nível médio, na modalidade normal.

Entretanto, independente de uma formação em nível médio ou em nível superior, não basta apenas incluir nos currículos de formação de professores disciplinas que dizem respeito à inclusão e à capacitação de professores quanto ao atendimento à pessoa com deficiência, sem nenhuma experiência teórico-prática.

Os professores deveriam ter uma especialização adequada, independentemente do nível de escolaridade dele, capacitando-os para a inclusão dos educandos nas classes regulares. Porém, apesar de tudo, ainda que não haja uma especialização adequada, isso não significa que não possa haver inclusão. $\mathrm{O}$ professor que está envolvido de verdade com a educação precisa ter um olhar diferenciado, um olhar comprometido, um olhar com perspectivas para aquele aluno que a sociedade vê como incapaz.

Segundo a LDB, 9394/96:

Art. 59. Os sistemas de ensino assegurarão aos educandos com deficiência, transtornos globais do desenvolvimento e altas habilidades ou superdotação: (Redação dada pela Lei no 12.796, de 2013). III - professores com especialização adequada em nível médio ou superior, para atendimento especializado, bem como professores do ensino regular capacitados para a integração desses educandos nas classes comuns.

Todavia, para a melhoria da qualidade do ensino, não basta apenas esforços isolados dos professores; a escola não é só feita por professores, ela se constitui por uma vasta equipe que unida pode fazer a mudança.

\section{Atual situação das escolas do Rio}

O Instituto Municipal Helena Antipoff (IHA) é o órgão da Secretaria Municipal de Educação responsável pela Educação Especial nesta Rede Pública de Ensino. O IHA, através das Equipes de Acompanhamento, auxilia o trabalho das 11 Coordenadorias Regionais de Educação no sentido de garantir uma educação de qualidade para os alunos com deficiência, transtornos globais do desenvolvimento/ tea e altas habilidades/superdotação. Além disso, promove ações de formação inicial e continuada para os profissionais da educação, em atenção ao imperativo de atender às especificidades dos alunos, respeitando ritmos de aprendizagens diferenciados e apostando nas possibilidades desses sujeitos. 
Tais ações contam, inclusive, com o apoio de reconhecidos pesquisadores de universidades parceiras.

A Rede Pública de Ensino prioriza a inserção dos alunos público-alvo da Educação Especial em classes comuns, assegurando o Atendimento Educacional Especializado (AEE) em Salas de Recursos Multifuncionais, em consonância com o preconizado na Política Nacional de Educação Especial na Perspectiva da Educação Inclusiva (MEC, 2008). Existem, contabilizados, 464 espaços implementados. O AEE tem a função de auxiliar o processo de inclusão dos educandos, eliminando barreiras para a plena participação deles nas atividades propostas no cotidiano escolar. Cabe notar que este atendimento não é substitutivo ao processo de escolarização, sendo ofertado no contraturno do horário escolar dos alunos.

Trazemos aqui um panorama, em números, da Rede Municipal de Ensino do Rio de Janeiro: as unidades de Educação Infantil do Rio de Janeiro contam com 514 escolas, com o total geral de 138.431 alunos. Há 55.299 alunos matriculados em creches e 83.132 na Pré-Escola. Fazem parte do corpo docente 5.017 professores de Educação Infantil e 5.534 agentes de Educação Infantil. O último concurso realizado em 2015 para professores de educação infantil, carga horária 40 horas, exigia apenas formação em ensino médio, modalidade normal.

A Prefeitura do Rio tinha uma meta de até dezembro de 2016 construir 305 novas unidades escolares.

\section{Pesquisa Preliminar de Dados}

Foi feita uma Pesquisa Preliminar de Dados com 20 professores da educação infantil da rede pública da Prefeitura do Rio de Janeiro.

Foram realizadas conversas, observações em diversas escolas, EDIs e creches da Prefeitura do Rio de Janeiro.

Observando o perfil dos participantes da amostra, é possível constatar que todos os entrevistados são do sexo feminino e atuam nas seguintes CREs (Coordenadoria Regional da Educação do Rio de Janeiro): $1^{\text {a }} \mathrm{CRE}, 5^{\mathrm{a}} \mathrm{CRE}, 6^{\mathrm{a}} \mathrm{CRE}, 7^{\text {a }} \mathrm{CRE}, 9^{\mathrm{a}} \mathrm{CRE}$ e $10^{\text {a }} \mathrm{CRE}$. As idades variam entre 21 e 67 anos, algumas possuem apenas o curso normal formação de professores, outras estão cursando o ensino superior em pedagogia, outras ainda possuem graduação no curso de pedagogia e outra em fonoaudiologia; foi verificado também que algumas possuem pós-graduação lato senso.

A jornada de trabalho gira em torno de 40 horas semanais, podendo chegar até 45 horas semanais quando fazem hora extra; existem também jornadas de trabalho de 22h30min semanais. Há profissionais que trabalham na educação infantil há mais de 10 anos. Muitas possuem formação continuada, e aquelas que possuem apenas o curso normal investem na graduação em pedagogia; aquelas que já possuem formação em pedagogia participam de palestras e cursos nas áreas de inclusão, educação infantil e cotidiano escolar e/ou investem em pós-graduação nas áreas de educação, psicopedagogia, neuropsicopedagogia e gestão educacional.

A formação continuada de professores e gestores educacionais da rede pública de ensino pode contribuir para uma visão mais alargada da educação inclusiva.

A formação dos professores dá condições necessárias para que as práticas integradoras sejam positivas, pois o professor ao se sentir pouco competente pode vir a desenvolver além de expectativas negativas, menor interação e atenção dos alunos (SILVA, 2009, 
p.24)

A maior parte das professoras tem ou já teve um aluno com deficiência e os incluiu através de conversas prévias com a turma, percebendo quais são as necessidades educativas daquele estudante, respeitando seus limites, realizando as adaptações necessárias dos materiais e das atividades, utilizando buscas na internet sobre inclusão e sobre as deficiências para ampliar seus conhecimentos e estimulando o grupo a interagir entre eles; segundo os entrevistados, esse processo ocorre naturalmente.

Durante a conversa, foi apresentada, entre outras, a seguinte questão: O que acha da inclusão na rede pública pensando na educação infantil? As respostas predominantes foram que a inclusão é muito importante, necessária, desafiadora, porém difícil, utópica e precária, devido à falta de apoio de outro profissional em sala de aula além do professor, à falta de recursos, à falta de mobiliário adequado e à falta de formação adequada para os profissionais que atuam diretamente na inclusão. Nas respostas, pode-se destacar a fala de uma das entrevistadas: "Acredito na inclusão, apesar de ser um desafio que envolve várias pessoas. Ela é necessária, porém faltam profissionais qualificados e um suporte adequado" (Participante R).

Para a maioria das professoras, a visão e as perspectivas mudam em relação à criança com deficiência, porque ela precisa de maiores cuidados e atenção, possui um desenvolvimento diferenciado e comportamentos diferentes, necessita de apoio e acompanhamento na sala de recursos. O professor precisa mudar o seu planejamento, criar estratégias para a realização das atividades, pesquisar sobre a deficiência, suas limitações e suas possibilidades de aprendizagem, construir uma prática pedagógica diferenciada voltada para a inclusão. Algumas se sentem receosas, pois não foram preparadas para trabalhar com essas crianças, outras acreditam que seu próprio psicológico apresenta um estranhamento, mas que se naturaliza com o tempo. Aqui, uma outra fala pode ser destacada: "A visão muda sim, mas tão somente para ter um olhar mais atencioso às pequenas mudanças. As perspectivas são as mesmas para a turma toda, porém os limites de cada criança precisam ser respeitados" (Participante ME).

Poucas acreditam que a sua visão e suas perspectivas não mudam em relação à criança com deficiência, porque possuem uma expectativa com todos os seus alunos, acreditam que a criança com deficiência é uma criança como qualquer outra, preferem tratá-la e torná-la independente para se sentir parte do grupo, avaliam que todos têm suas deficiências, mas as suas especificidades precisam ser levadas em consideração.

Uma outra questão foi formulada durante a conversa: Quais os benefícios que um aluno com deficiência na educação infantil tem ao frequentar uma escola regular? As respostas citaram, como benefícios, a interação, socialização, naturalização, ausência de preconceito, autoestima, desenvolvimento social e motor, novas experiências, desafios e vivências, superação, troca, estímulos, respeito ao outro, brincadeiras, afetividade, solidariedade, cidadania e inserção social.

A educação inclusiva tem sido caracterizada como um "novo paradigma", que se constitui pelo apreço a diversidade como condição a ser valorizada, pois é benéfica à escolarização de todas as pessoas, pelo respeito aos diferentes ritmos de aprendizagem e pela proposição de outras práticas pedagógicas, o que exige a ruptura com o instituído na sociedade e, consequentemente, nos sistemas de ensino (MANTOAN; PRIETO, 2006, p. 40).

Uma outra questão foi apresentada: Quais os desafios enfrentados por um professor que tem que lidar com alunos incluídos? Os participantes apontaram o despreparo, a falta de estrutura adequada, a falta 
de orientação, a falta de adaptações necessárias, a falta de um suporte de um profissional, a falta de recursos, turmas lotadas, o desconhecimento sobre a deficiência, a dificuldade de aceitação da família e o desafio de conseguir garantir a interação e o aprendizado apesar de todos os problemas.

Pode-se constatar que são muitos desafios enfrentados e que a maioria deles não depende única e exclusivamente do professor. Para Glat, 2007, p.21,

Para tornar-se inclusiva a escola precisa formar seus professores e equipe de gestão, e rever as formas de interação vigentes entre todos os seguimentos que a compõe e que nela interferem. Precisa realimentar, sua estrutura, organização, seu projeto político-pedagógico, seus recursos didáticos, metodologias e estratégias de ensino, bem como suas práticas avaliativas. Para acolher todos os alunos, a escola precisa, sobretudo, transformar suas intenções e escolhas curriculares, oferecendo um ensino diferenciado que favoreça o desenvolvimento e a inclusão social.

Surgiu um outro questionamento: O que é indispensável na sala de aula de educação infantil em que há um aluno com deficiência? As entrevistadas apontaram que o apoio de outro profissional é indispensável, a adaptação dos espaços, dos mobiliários e dos materiais, o tempo para planejar, acessibilidade, redução do número de crianças em sala, suportes tecnológicos, paciência e amor.

Pensar na sala de aula como construtora de subjetividades e lugar privilegiado de inclusão nos remete a uma reflexão sobre as práticas pedagógicas dos (as) professores (as) que apontam para a construção social do sujeito (REMENCHE; GONÇALVES, 2007, p. 2150).

A sala de aula é um espaço em que o reconhecimento de valores distintos entre os vários grupos existentes na sociedade e o olhar atento às diferenças devem ser praticados. Como espaço educacional, pode colaborar, ou não, para que o sujeito se torne parte/membro de um grupo social.

\section{Considerações finais}

Através deste trabalho foi possível identificar múltiplos olhares sobre a inclusão na rede pública do Rio de Janeiro.

Olhar atento, olhar inquiridos, olhar respeitoso, olhar indiferente, olhar cruzado, (com) partilhado, olhar terno, olhar desejo, olhar desejo, olhar suplicante, olhar expressivo, olhar padrão, olhar perdido, olhar compreensivo, olhar aterrorizado/r, olhar dominador, olhar sublime, olhar estranho, olhar alienado, olhar amoroso, olhar narcísico, olhar ponta-de-bengala, olhar interior, profundo, penetrante, auscultante, olhar de astronauta, [...]. Olhar unidirecional! Múltiplos olhares! (BIANCHETTI, 2002, p.2).

Dentre os entrevistados, prevalece o olhar positivo sobre a inclusão, porém com muitos desafios e obstáculos que podem ser superados a partir de políticas pública de inclusão. 
Portanto, um olhar diferenciado do professor é decisivo para eliminar barreiras da inclusão. O professor ao considerar que as necessidades educacionais especiais do seu aluno com deficiência, se encontram na relação entre o seu processo de aprendizagem e a proposta curricular desvia-se o foco de atenção, que antes era voltado e centralizado nas dificuldades do aluno, direcionando para as propostas educacionais que a escola promove para beneficiar seu aluno.

Cada criança tem uma especificidade independente de ser criança com deficiência ou não; ter um olhar diferenciado auxilia na busca por estratégias de ensino. A mudança ou não de visão e perspectiva é muito relativa e muito pessoal, mas o importante é que, havendo mudança ou não, é necessário sempre ter um olhar voltado por uma ótica de expectativas positivas.

A diferença surge como uma mais-valia, como uma oportunidade de desenvolvimento. Não basta incluir fisicamente; toda a comunidade escolar precisa estar envolvida no processo educacional. $\mathrm{O}$ preconceito é construído socialmente. Sempre que nos deparamos com uma interação social, "automaticamente" tentamos encaixar a pessoa (ou a situação) em uma categoria conhecida. Interações sociais e primeiro contato são avaliações de situações.

Quando as diferenças ou características são avaliadas negativamente, forma-se o estigma (GLAT, 2004), e esse estigma funciona como um rótulo. A socialização o estimula a vencer novos desafios, fazendo-o se sentir cada vez mais capaz. A criança cresce e aprende a viver em ambientes integrados, estabelecendo significativos laços de amizade.

Tais benefícios não se aplicam somente para os próprios alunos com deficiência, mas também para os demais colegas de turma e demais componentes da comunidade escolar.

Para os alunos com deficiências, a inclusão possibilita que eles ocupem um espaço antes não ocupado. Passam a exercer seus direitos e tornam-se cidadãos, convivendo com todos os outros alunos da escola.

\section{Referências}

AINSCOW, Mel. Tornar a educação inclusiva: como essa tarefa deve ser conceituada? In: FÁVERO, O. et al. (Orgs.). Tornar a educação inclusiva. Brasília: UNESCO, 2009.

BARROS, A. C. de C. Faces e contrafaces dos educadores com deficiência, 2003. 187 f. Dissertação (Mestrado em Educação) - Universidade de Uberlândia, 2003.

BIAGGIO, Rita de. A inclusão de crianças com deficiência cresce e muda a prática das creches e pré-escolas. Revista Criança, Brasília, n.44, p.19-26, nov.2007.

BIANCHETTI, L. Um olhar sobre a diferença: as múltiplas maneiras de olhar e ser olhado e suas decorrências. Revista Brasileira de Educação Especial, Marília, v. 8, n.1, p. 1-8, 2002.

BRASIL. Constituição da República Federativa do Brasil. Brasília, 1988. Disponível em:< www. planalto.gov.br.> Acesso em: 20 maio 2017.

BRASIL. Lei de Diretrizes e Bases da Educação Nacional, № 9394. Brasília, 1996.

. Política Nacional de Educação Especial na Perspectiva da Educação Inclusiva. Brasília: MEC/SEESP, 2008. Disponível em:< www.mec.gov.br.> Acesso em: 20 maio 2017.

- Ministério da Educação. Resolução no 4: Diretrizes Operacionais para o Atendimento Educacional Especializado na Educação Básica, modalidade Educação Especial. Brasília, 2009. 
BRAUN, P.; VIANNA, M. M. Atendimento educacional especializado, sala de recursos multifuncional e plano de ensino individualizado: desdobramentos de um fazer pedagógico. In: PLETSCH, Marcia Denise; DAMAECENO, Allan (Org.). Educação especial e inclusão escolar: reflexões sobre o fazer pedagógico. Rio de Janeiro: UFRRJ, 2011. v. 1, p. 23-34.

CARMO, Apolônio A. Deficiência física: a sociedade brasileira cria, recupera e discrimina. Brasília: Secretaria dos Desportos, 1991

DRAGO, Rogério. O bebê com deficiência na educação infantil: perspectivas inclusivas. In: ÓRRU, Silvia Ester. (Org.). Estudantes com necessidades especais: singularidades e desafios na prática pedagógica inclusiva. 1ed. Rio de Janeiro: WAK, 2012. v. 1, p. 63-89,

FERREIRA, M. E. C.; GUIMARÃES, M. Educação inclusiva. Rio de Janeiro: DPeA, 2003.

GLAT, R. A integração social dos portadores de deficiência: uma reflexão. 3. ed. Rio de Janeiro/ RJ: Sete Letras, 2004. v. 1,69p.

GLAT, R.; BLANCO, L. de M.V. Educação especial no contexto de uma educação inclusiva. In: Rosana Glat. (Org.). Educação inclusiva: cultura e cotidiano escolar. Rio de Janeiro: Sete Letras, 2007, V., p. 15-35.

GLAT, R.; FERNANDES, E. M. Da educação segregada à educação inclusiva: uma breve reflexão sobre os paradigmas educacionais no contexto da educação especial brasileira. Inclusão. Revista da Educação Especial, Brasília, n.1, p. 35-39, out. 2005.

JANNUZZI, Gilberta De Martino. Políticas públicas de inclusão escolar de pessoas portadoras de necessidades educacionais especiais: reflexões. Revista GIS, Rio de Janeiro, out.2004. Seção artigos. Disponível em: <http://www.cereja.org.br/pdf/20041220_Gilberta.pdf>. Acesso em: 28 mar. 2016.

JOBIM e SOUZA, S. Dialogismo e alteridade na utilização da imagem técnica em pesquisa acadêmica: questões éticas e metodológicas. In: FREITAS, M. T. A.: JOBIM e SOUZA, S.; KRAMER, S. (Org). Ciências humanas e pesquisa: leituras de Mikhail Bakhtin. São Paulo: Cortez, 2003.

LITWINCZUK, Lilian. Educação especial inclusiva no Brasil : trajetória histórica. Cianorte, 2011.

MENDES, Enicéia Gonçalves. Breve histórico da educação especial no Brasil. Revista Educación y Pedagogía, Medellín, Universidad de Antioquia, Facultad de Educación, v. 22, n. 57, maio /ago. 2010.

MANTOAN, Maria Teresa Eglér; PRIETO, Rosângela Gavioli. Inclusão escolar- pontos e contrapontos. São Paulo. Summus 2006.

PARANÁ. Secretaria de Estado da Educação. Superintendência da Educação. Diretrizes curriculares da educação especial para a construção de currículos inclusivos. Curitiba, 2006.

REMENCHE, M. L. R.; GONÇALVES, A. A. O. Inclusão e sala de aula: entrelaçamento necessário na constituição do Sujeito. In: EDUCERE, 2007, Curitiba. EDUCERE. Curitiba: Champagnat, 2007. v. 7. p. 2144-2154.

RIO DE JANEIRO. Secretaria Municipal de Educação - Disponível em: <http://www.rio.rj.gov.br/ web/sme/educacao-especial> Acesso em: 19 nov. 2016.

SILVA, L. M. Educação inclusiva e formação de professores. Especialização em Educação Profissional e Tecnológica Inclusiva. Brasil : Instituto Federal de Mato Grosso, IFMT, 2009. 